\title{
Chronic pain: a concept analysis
}

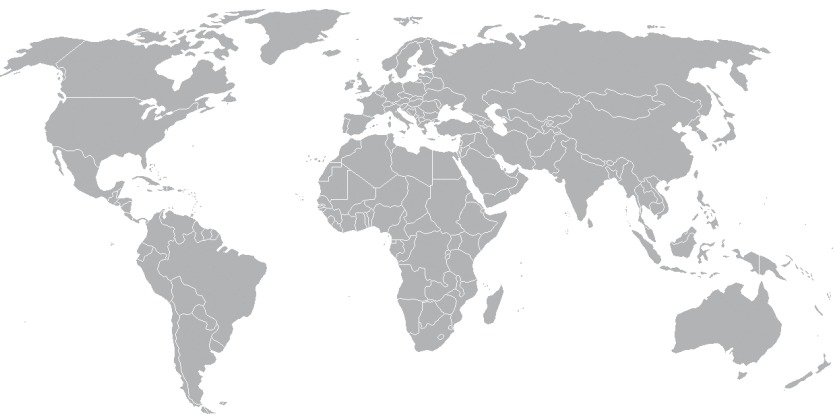

\author{
Khatereh Rostami ${ }^{1}$, Saeed Hamidi Zadeh¹, Mahnaz Rakhshan ${ }^{3}$
}

\begin{abstract}
Background and Objective: The concept of chronic pain is a significant nursing notion for which there are various definitions and patterns mentioned in texts. Thus, this survey was carried out to analyze the concept of chronic pain with respect to more clarifications on this concept in nursing with an evolutional approach.

Materials and Methods: In the present study, Rodgers evolutional method for concept analysis was used. The sources where the required data for analysis was obtained were Nursing Index, ProQuest, and Ovid databases. The criteria for entering these databases were English texts published from 1995 to 2016 years. The keywords used for searching in titles were acute pain, interact abele, trauma pain, non-cancer pain.

Results: In this study, the features of chronic pain were identified as being long, killing, and having visceral nervous roots. The symptoms for this pain are characterized as hurting, acute pain, and passing the acute pain. Its aftermaths consist of physical and psychological disorders, economic problems and lack of appropriate welfare in life.

Conclusion: According to the findings of the present study, it is possible to present a theoretical definition for chronic pain concept. The results may help other researchers in developing a model and theory related to this topic by illuminating the chronic pain concept and regarding the fact that theories are building blocks for formulating theories.
\end{abstract}

Keywords: chronic pain, qualitative survey, concept analysis, Rodgers evolutional approach

\section{INTRODUCTION}

Chronic pain is a very common, expensive disability which can affect everybody at any age and may cause different levels of disability to occur (1). According to Medical Expenditure Panel Survey report in 2008, about 100 million adults suffered chronic pain (2). Also, as stated in researches by National Health and Wellness survey in UK, France, Spain, Germany, and Italy, It has been revealed that 50 million people suffer chronic pain in these countries (3).

Chronic pain, traditionally, is a type of pain that continues more from its usual amount. International Association for the Study of Pain (IASP) defines chronic pain as a kind of pain which has no specific biological symptoms and its duration extends the time needed for tissue healing (usually 3 to 6 months) (4). In contrast, American College of Rheumatology identifies chronic pain as a pain starting in two parts of four upper and lower body parts or in the axial skeleton and lasting for three months (5).

Non-cancer chronic pain (CNCP) or simply chronic pain is a common status which affects people of all age groups in different forms; people both suffer from the pain and its long period continuance(6). The most common cases of CNCP are neuropathic pain, fibromyalgia, chronic headache, myofascial pain syndrome, and chronic low back pain (1). Studies conducted in 2010 show that medium to severe chronic pain can have effects on people's daily activities like their work, house chores, recreation, and communications (6). In addition, it may decrease the quality of life and physical and mental balance abilities so as to affect health, emotional wellbeing, and all aspects of life (7). Seeking a serious treatment can cut down the pain, improve health condition and increase the quality of life $(6,8)$. Chronic pain is a concept having many applications in clinics; therefore, such notions are recognized as the building blocks of theories and have remarkable role in formulating them $(9,10)$. There are many approaches that researchers have used to develop these concepts including concept analysis which investigates the main elements of a concept with the aim of structure recognition and its function

\footnotetext{
1 Student Research Committee, School of Nursing and Midwifery, Shiraz University of Medical Sciences, Shiraz, Iran

2 Community Based Psychiatric Care Research Center, School of Nursing and Midwifery, Shiraz University of Medical Sciences, Shiraz, Iran
}

Received: 13 Apr 2018, Accepted: 3 Jun 2018

\author{
Correspondence: Mahnaz Rakhshan \\ Community Based Psychiatric Care Research Center, School of Nursing and \\ Midwifery, Shiraz University of Medical Sciences, Shiraz, Iran \\ E-mail:mzrakhshan@gmail.com
}

(C) 2019 by the authors; licensee Modestum Ltd., UK. This article is an open access article distributed under the terms and conditions of the Creative Commons Attribution License (http://creativecommons.org/licenses/by/4.0/). 
Table 1: The phases of Rodgers evolutional concept analysis

\begin{tabular}{ll}
\hline Phases & Actions \\
\hline Phase1 & Determining the sought concept and its accompanying statements and alternatives \\
\hline Phase2 & Determining and choosing the appropriate realm (collection and the sample) for collecting data \\
\hline Phase3 & $\begin{array}{l}\text { Collecting data related to the features of the concept in accordance with contexture changeabilities like social, cultural, interdisciplinary and } \\
\text { periodical sources (appearance of symptoms and aftermaths for the concept) }\end{array}$ \\
\hline Phase4 & Analysis of the data based on the features of the concept \\
\hline Phase5 & Exemplifying based on the concept in case of necessity \\
\hline Phase6 & Introducing assumptions for complementing the concept \\
\hline
\end{tabular}

(11). The theorists, researchers and clinical specialists get involved in probabilities and different concept derivatives in the process of concept analysis and recognize them. Each concept has features which make it distinctive from the others. Concept analysis is not only useful in purification of vague concepts of theories but also can clarify the concepts that have had applications in nursing, have been ambiguous and utilized improperly or extremely (12). During several decades ago, various methods for analyzing concepts have been developed, each based on its own philosophical backgrounds; this may result in outstanding effects on accomplishment, interpretation, and application of the analysis outcomes (11). Rodgers evolutional analysis of concept is based on contemporary thinking philosophy related to concepts and their role in evolution and progress of knowledge. This approach emphasizes the dynamic nature of concepts which was constantly changing through the time in the social contexture (12). In the evolutional attitude, instead of answering the question "what is the sought concept?" exploratory approaches are mainly emphasized. In such situation, contrary to most analysis methods, the acquired results are not meant to be the end of the analysis, but they are seen as a new starting point. The evolutional concept analysis method is generally based on inductive approach and has always a basis available for more investigations in the future (13).

The contemporary nursing believes that the human truth and nursing phenomena related to it are constantly changing and they have interrelated elements; since this approach is in accordance with Rodgers concept, it is used for related studies (14). Therefore, this study was conducted with the aim of clarifying the chronic pain concept, more understanding and recognition of features, symptoms and aftermaths of chronic pain and its changes through the time. It is hoped that the outcomes of this explanation for the concept become the common cases of use and clarification of its characteristics as the basis for more developments of the concept.

\section{MATERIALS AND METHODS}

The present study is the analysis of concept with Rodgers attitude. In this approach, although the primary hexaploid activities have been advised (Table 1), Rodgers believes that many of these activities are done during the study simultaneously. The process of investigation has a non-linear, circular, and flexible nature. The hexaploid phases merely express the activities that must be done during the study and should not be regarded as sequential. In this method, Rodgers has exploited an inductive, particular analyzing method; thus, the focus of this study is on collecting and analyzing raw data. Also, concepts of certain social, cultural, and context in any profession are studied $(12,13)$.

According to Rodgers evolutional approach which is based upon raw data available in literature, the PubMed, ProQuest, Ovid, and Nursing Index databases were chosen for performing the searches. In an elementary search for pain terminology, pain, chronic pain, and chronic were used separately and in combination. In the next steps, the criteria for entering texts into the study were determined in order to achieve more exact results.

The keywords used in searches were the following:

Intractable pain, non-cancer pain, nonmalignant pain, chronic pain, persistent pain, pain perception, pain duration, pain chronification, pain chronicity, acute pain and trauma.

To gain more exact results, the criteria for entering texts to study were determined. The main criterion for arriving at the final analysis was the publication of the texts in English during the years 1979 to 2016 and appearance in the context of chronic pains. From 2132 articles reviewed, 1102 were related to nursing, 1004 to medicine, and 26 to physiology. Among this large number of articles, only 152 of them which were directly related to chronic pain were chosen and then 80 articles were selected randomly for analysis. 4 nursing books were also used aiming at covering topics related to the concept in the analysis process.

After reading each article, they were classified according to focusing on chronic pain; therefore, they were categorized in the symptoms and aftermaths group. The books were equally read and reviewed deeply and the information related to the features, symptoms and aftermaths of the concept and the alternative terms were summarized and encoded. 
With the help of thematic analysis and iterative processes, the preliminary themes were drawn and then classified in the form of the concept features. In order to guarantee impartiality, add credit, and decrease leaning, the analysis process was verified by two profound concept analysis experts.

\section{RESULTS}

Features: Identifying the concept features is the first step to do the analysis which results in a definition for concept. Features are the key characteristics that present an authentic definition for concept and make the determination of the conditions and concept realization possible (12). The descriptions must be categorized based on the number of occurrence of the concept feature (15). In this study, the features of chronic pain have been obtained based on theme analysis process. One of the most notable features is durability which has been defined in two ways in different theories; one states the pain duration as lasting for three months; the other claims the same situation lasting more than six months after the symptoms appearance $(16,17)$. According to some other theories, the acute pain lasts less than 30 days and the chronic pain is the kind that is endured more than six months. They also believe that sub-acute pains are those which last from one to six months (18). But the most important definition can be as follows: the pain that has lasted more the expected healing time (17). The standard definition provided in the medical dictionary for the term "chronic" is "long period of time"(19); this definition matches the ones presented by International Association for the Study of Pain (IASP) for chronic pain, meaning the kind of pain that does not have biological symptoms and is endured more than the healing time needed for body tissues. However, the healing time for body tissues is important too because they may need different periods of time for healing in different injury cases (20). In the case of non-cancer pains, three months is the most acceptable time to distinguish chronic pain from acute pain but for research purposes, six months is the preferred time (21). the definition of pain which is based on time supports only the viewpoint that acute pain is rooted in signals caused by an injury in the tissue, while chronic pain is the result of agitations from the brain or environment in which the pain appears after the decrease of agitation to the nociceptor; therefore, the clinical importance of the chronic pain is not merely based on its lasting long or not, but is known by the influence it has on people's lives. For example, there are many people who suffer backache, but they are living a normal life $(20,22)$.

Chronic pain may be rooted in the body, brain, or spinal cord. It is a pain whose treatment is difficult and usually is controlled via managing the pain. Some of them are manipulated using opioid treatment which can hurt people $(23,24)$. In some cases, non-opioid drugs may be used; it depends on whether the pain is in the tissue or it is neuropathic (25, 26).

Chronic pain can be fatal in the first ten years. The most common reasons are heart disease, respiratory disease or depression in these people. Impatience, sleep disorders, and neuroticism are interrelated with chronic pain inasmuch as it may cause a decrease in physical activities due to fear of the pain growing stronger consequently leading to weight gain. Pain sensitivity, control, and resistance are all affected by various social supports that a person suffering from chronic pain may receive $(25,26)$.

There are two different types of chronic pain: 1. Nociceptive which is developed because of an injury to the tissue, and 2. Neuropathic that is caused by an injury or malfunction in the neural system (27). Nociceptive pain is divided into two types: Superficial and Deep. The deep type is also divided into Visceral and Deep somatic. The superficial pain is created by the activation of nociceptors in the skin or superficial tissues. Deep somatic pain is caused by the agitation of nociceptors or ligaments, tendons, bone, blood vessels, or fasciae muscles that may be in dull, aching, or poor localized forms. The source of visceral pain is in viscera organs and this pain can be well-localized. But it is not often centralized hence leading to referred pain (28). The neuropathic pain is divided into Peripheral (rooted from PNS) and Central (rooted from the brain and spinal cord). The neural peripheral pains are often accompanied by the words burning, tingling, electrical, stabbing, and pins and needles (29-31).

Pain definition: ISAP stated that pain is an unpleasant, emotional experience that is accompanied by a definite or probable injury to the tissue. In a broader definition of pain, it has always been subjective that is with biological, psychological, and behavioral parts and occurs following a definite or probable injury to the tissue. In this definition, it is clear that people do not consider pain as a result of injury to the tissue or pathophysiological reasons but they believe the causes of pain are psychological $(32,33)$. Some people argue that pain is a multidimensional experience having neurophysiological, biomedical, psychological, affective, cognitive, ethnological, spiritual, religious and environmental dimensions (34).

Chronic pain: chronic pain that is one of the most widespread reasons for receiving treatment services can be the result of injury to the tissue, nerve or simply a part of different levels of a disease or it may be idiopathic. It also can have 
psychological parts and cause uneasiness, depression, and psychosomatic disorders. Chronic pain is distinguished from acute pain with regard to the lasting period, physiologic mechanism and potential effects on the individual's productivity and life. Insufficient treatment leads to negative effects on health, decrease in the quality of life or unpleasant events (35).

Surrogate terms: Surrogate terms are concepts that have many things in common with the mentioned concept and in some cases due to the content nominal similarity, they may be used instead of the original concept, but they are not the concept itself (12).

One of the surrogate terms is non-cancer pain. The pain that lasts at least three months or more period of time than the expected one for the tissue healing is called non-cancer pain (36). This pain is identified by uneasiness, depression, less productivity and increased treatment expenses (37). In this situation, the disease lasts at least six months and patients suffer a minimum of two times pain experience a week (38). Another substitute term is intractable pain. These groups of patients are those with (CRPS) complex regional pain syndrome type1, sympathetic dystrophy, or neuralgia posttherapeutic (PTN) and other neurologic pains. The symptoms can be pain in bottom organs in different patients suffering from HIV, diabetes, and poly- neuropathies. The pain can spread rapidly in the patients with advanced diseases, for instance patients who suffer the CD4<50 HIV level. The symptoms may also include insentience, sting, pins and needles, weakness, cramp (39). This pain plays an important role in weakening the patients. Such pains are usually very resistant to edible narcotics and prenatal $(40,41)$. The other term that is used to refer to chronic pain is persistent pain. It means the kind of pain which lasts for long days and period and is created due to hurting the tissue or nerves. This lasting pain is detected by long lasting changes it causes in the nerve system and approved evidence of spreading dorsal horn hyperexcitability, activity dependent plasticity, or agitation of the central nerves (42). It can also be recognized by the CNS inflammation and the immune response in diagnosing the neurologic diseases like Parkinson, traumatic brain, stroke, spinal cord injury, and MS (43). All these diseases have long lasting pain and they all share the neurodegenerative feature. In the case of persistent pain, the important point is the existence of neuro-inflammation and neuro-immune activation (43).

Related Terms: The related terms are the concepts which have a certain relation with the concept but do not possess all the characteristics of it. Meanwhile, the related term and the mentioned concept influence each other. Management of chronic pain, cancer pain, and physical dysfunction are examples of the related terms.

Management of chronic pain: The regulations applied to manage chronic pain are guidelines which are applied during a management process in order to decrease pain in the patients. Management services prepared by certified registered nurse anesthetist (CRNA) are based on the condition of the patients, their maintenance, and their needs (44). Management of chronic pain goes beyond just decreasing the pain in as much as it comprises the improvement of the quality of life and their eligibility for being employed and being generative to enjoy life (45).

Another term related to chronic pain is physical dysfunction. Chronic pan can affect daily activities negatively; hence, disappearing of chronic pain results in improvement of the patient's productivity and quality of life in a way that pain intensifying has a reverse relation with the quality of life (46). Cancer pain, another term related with chronic pain is an integral part of many cancers and causes many problems for the patient. In addition to destructive effects it has on the patient, it takes away the most helping potentials of his family and curing team; it may continue until it reaches an unbearable point. Uncured pains can impose a great emotional pressure on both the patient and his family (47).

Antecedent: Antecedent are events that occur before the concept or have a previous relation with it (12). In reviewing the texts, these Antecedents consist of trauma, acute pain, and transfer from acute pain to chronic pain. The term trauma means injury, so it is not only an incident but works as a combination of psychological, biological, social and other environmental factors. In most cases, trauma may lead to bleeding and eventually death of the patient; therefore, it can be a disastrous event (48).

Acute pain is often created by an injury to the tissue, surgery operation, bone fractures, dental problems, burnings, cuts, and childbirth pains. Thus, it does not last more than six months and as soon as the cause is gone, the pain disappears, too. Some pains, if not cured, may grow from acute level to chronic (49). The passing from acute to chronic pain phase: The passing phase means going from one situation into another (19). There are factors like psychological, genetic, and behavioral, the pain intensity, heart attack or a recent disease and treatment failure which can direct the patient from acute phase of pain to this stage. In this phase, people who have certain characteristics or are in the pain prone group of people have more potential for entering the chronic pain phase (50). The passing phase can take a two month process from acute pain to arrive at chronic pain level after the acute active injury, and then this phase can cause disability, depression and nervous pressures generally known as failure to adapt. In this phase, pain feeling appears less 
and causes emotional reactions like uneasiness, emotional distress or depression in this phase. Social factors can intensify such experiences (51). Consequence: Events happening subsequent to the mentioned concept represent the outcomes (52). Narcotic addiction, psychological problems like social isolation, increased stress, violence, decreased life and sleep quality, physical problems like cardiovascular problems, decreased sexual performance, and increase in economic costs are the results of chronic pain. Narcotic addiction: While healing narcotic is accepted as a remedy for chronic pain, its efficacy and safety in curing is still ambiguous $(53,54)$. Doctors say that they are worried about patients getting addicted to narcotics when they prescribe them as the remedy for their chronic pains $(55,56)$. Since the majority of people suffering chronic pain use narcotics to relieve their pain, the patients and treatment team's concern is about creating a dependency and side effects to these drugs (57). Chronic pain can be the reason for psychological problems like anxiety, depression, or somatization disorders, suicidal thoughts and committing suicide; it can have negative effects on the quality of people's lives and sleep patterns. Chronic pain causes destructive effects on people's health, job, daily life quality which is rooted in disability created by chronic pain. Chronic pain has also negative effects on physical and social performance; physical, emotional, and mental health; and general health and energy (58). Sleep disorders are largely seen in people suffering chronic pain. Increase in chronic pain intensity can lead to an increase in insomnia, tiredness, sleepiness during the day and low mood (59). Chronic pain has negative effects on physical performance of the body like cardiovascular health (60). As stated in the recent researches, chronic pain causes increased hypertension constantly and it seems that chronic pain can interfere in the process of controlling blood pressure. Hypertension in such patients is above the normal, even in the resting time (61). Among other side effects of chronic pain is disorder in sexual performance (62). Studies conducted by different people show sexual problems in patients suffering chronic pain. Many of these patients avoid sexual contacts due to their concern about the pain intensifying or because they cannot take the right position because of their pain. Other reasons for sexual problems include having problem in arousal, confidence, performance or extreme fear from pain intensity and communicating problems (63).

References: References are settings and situations in which the mentioned concept is used. This concept is used in practical environment, clinics, social and old people's homes. One of the places where chronic pain and its treatment are considered is clinics and physician offices (53). Doctors face entanglement when they have to prescribe narcotic drugs for patients suffering chronic pain. On one hand, patients with chronic pain need narcotic drugs to control the pain; on the other hand, developing a drug resistance is an issue that comes up (35). Also, other places that may deal with the chronic pain concept are clinics. In order to manage chronic paining clinical settings, people holding health and treatment related jobs should be aware of chronic pain and the patients' attitudes about it and the procedures used for confronting this pain. Additionally, people working in clinics must be aware of appropriate guidelines to control chronic pain and apply them (64). Another place where chronic pain is used and its administration is one of its priorities is old people's home (65). Managing chronic pain for the elderly and familiarity with flexible ways to confront this type of pain can noticeably increase their quality of life and cut down the pain managing costs (66). However, chronic pain is not considered a normal phenomenon for old people, but because of various subsequences it has for them and the hygiene system it should be strongly cured since its treatment may lead to a decrease in pain, improvement of health condition, and increase in the elderly quality of life (67).

Model case for chronic pain concept: A practical way for a better comprehension of efficient applications of the concept is providing a model case which contains all the main characteristics of it derived from real life, articles, or a one made up by the person in nursing or non-nursing settings (12). A patient suffering chronic pain was interviewed about his experiences and said: "14 years ago, I hurt my waist when lifting a heavy weight and since then I am suffering a chronic pain which is more stabbing; I can't sleep, lie down, bow, or walk rightly. I can hardly run; I must constantly be careful not to do any wrong movement to avoid extra pressure on my nerves or waist and this fear is always with me like a shadow. Even in sleep time, I must be cautious not to do anything that intensifies my pain. In the morning, when I wake up, I am still tired. I always have to use painkillers, but they are not useful anymore. I am really afraid of going under surgery. I hate walking or exercising. I am always sad and crying. My physical activity is zero and when I am nervous, I eat more. This low activity and overeating caused me to gain five more kilos compared to my weight last year. The treatment and physiotherapy costs are really high and I can't afford them. It has influenced all my life. I wish I could have a normal life."

Determining hypotheses and analyzing implications for more developments of the concept:

The final stage of Rodgers evolutional concept analysis consists of determining hypotheses and analyzing implications for more developments of the concept which provides a good opportunity to discuss the application of findings achieved by the concept analysis (12). The findings resulting from the concept analysis revealed that concepts like acute pain, 
chronic pain, hurt, and pass from chronic pain have a vital role in defining chronic pain as circumstances and they are well noted in Turk's definitions (2011) (68). One of the discussed hypotheses regarding chronic pain is the extension of this pain from the probable tissue healing time that ends in presenting different definitions about the duration of chronic pain. Since this pain does not have any stable feature, patients call it intractable pain (22).

Turk (2002) has stated some features for chronic pain based on its duration in order to distinguish it from acute pain and the passing stage from acute to chronic pain thoroughly (68). Also, Reuben et al. (2013) have defined different types of chronic pain with respect to its roots (23). Their definition has led to introduction of various forms of chronic pain. Due to the complicated nature of chronic pain, making different definitions for it is normal. According to Rodgers's evolutional approach philosophical basis, it can be inferred that the outcomes of concept analysis are not merely coming to a final answer for "what is concept?" but it is a basis for more exploitations and advancements of the concept. Based on the findings of the present analysis, the following definition can be derived. Chronic pain appears after an injury and then goes beyond passing acute pain phase; it finally reaches chronic pain; it lasts more than the time needed for tissue healing. This pain can be divided into different types of body, brain and medullar based on its root. It can also have various side effects like a decrease in quality of life and sleep; depression; cardiovascular, sexual, and movement disorders; weight gain, memory loss; financial problems; and generally biopsychosocial problems. considering the dominant philosophical attitude and Rodgers approach, presenting the above definition for clarification of chronic pain concept not only does not block the path for more explorations about the concept, but also provides an opportunity for future researches aiming at development of the concept and its applications in more fields like theorizing and investigating in pedagogical, administrating, and clinical realms.

\section{DISCUSSION}

Concept analysis not only represents the current level of knowledge about it but also illustrates the orientation of successive advancements (69). Conceptualization of chronic pain is of high significance in medical sciences. Chronic pain analysis helped the clarification of its dimensions and showed that chronic pain concept gives out different and sometimes opposite collection of meanings in the nursing literature and health related sciences. These features and the resulting outcomes from the analysis contribute to the clarification of the concept and lead to a distinction between the concept and other related concepts (9). The findings of the present study describes the chronic pain concept as a complicated, inevitable, constant and meanwhile an unpredictable concept in the process of evolution which is not known thoroughly; thus, its recognition increases the administrative abilities of the treatment personnel. The characteristics of this concept are its long duration and difficult process of cure. As the chronic pain is the unwelcome outcome of injury, acute pain and the passing from acute to chronic pain stages, the pain itself is the reason for unpleasant results. According to the review of the studies, the most important negative outcomes of the chronic pain are described as physical and emotional problems, economic burden and consequently the decrease in the quality of service users' lives $(59,61-63)$. It is obvious that unpleasant outcomes are always seen with this problem; specifically, its negative effects have been reported very noticeably and fatal. Hence, knowing the characteristics of chronic pain concept, its widespread symptoms and aftermaths, increasingly improves the applications, status and importance of this concept in nursing profession. Thus, it can be an exploratory layout for more investigations and development of the present knowledge in this profession. With the chronic pain concept being clarified, now, the criteria for evaluating the current situation of the service users can be devised. The concept analysis leads to a better comprehension of chronic pain concept in clinic, education, and researches. Thus, concerning the philosophical basis of evolutional approach, the results of the present study can provide an opportunity for more researches aiming at development of chronic pain concept and its application in theorizing and theory development fields, investigation in pedagogical, administrative, clinical and nursing, and development of evaluation tools for chronic pain in different disease.

Although features, symptoms and aftermaths of chronic pain concept in this study have helped to understand it, there are gaps in this regard which include limitation in discussing importance, application and use of chronic pain concept in different cultures and situations like Iranian culture, limits in testing measures based on theories and their evaluation of these measures about chronic pain concept. Therefore, expansion of a more extensive concept using exploratory and descriptive investigations in various cultures and settings can clear the background for this concept. Besides, devising and testing a theory related to chronic pain concept is a requirement for the development of nursing measures. This act can enable the nurses to fill the gap between weak and strength points in clinical settings and will be the basis of new caring models for chronic pains. 


\section{CONCLUSION}

With all these achievements now we can say that concept analysis has a temporary and tentative nature so new questions with the provided responses may be asked. This study was an attempt to begin the chronic pain concept analysis, hoping that investigating it enriches the concept among the authors and nursing scholars.

\section{ACKNOWLEDGEMENT}

Hereby, it is necessary to acknowledge Shiraz Medical University and the vice chancellor of Shiraz nursing school for their sincere supports in this project. The authors would like to thank Shiraz University of Medical Sciences, Shiraz, Iran and also Center for Development of Clinical Research of Nemazee Hospital and Dr. Nasrin Shokrpour for editorial assistance.

\section{REFERENCES}

1. Spacek A. Modern concepts of acute and chronic pain management. Biomed Pharmacother. 2006;60(7):329-35. https://doi.org/10.1016/j.biopha.2006.06.011 PMid:16814978

2. Gaskin DJ, Richard P. The economic costs of pain in the United States. J Pain. 2012;13(8):715-24. https://doi.org/10.1016/j.jpain.2012.03.009 PMid:22607834

3. Pergolizzi J, Ahlbeck K, Aldington D, Alon E, Collett B, Coluzzi F, et al. The chronic pain conundrum: should we CHANGE from relying on past history to assessing prognostic factors? Current medical research and opinion. 2012;28(2):249-56. https://doi.org/10.1185/03007995.2011.651525 PMid:22181344

4. Tauben D. Chronic pain management: Measurement-based step care solutions. Pain Clinical Updates. 2012;20(8).

5. Carnes D, Homer KE, Miles CL, Pincus T, Underwood M, Rahman A, et al. Effective delivery styles and content for self-management interventions for chronic musculoskeletal pain: a systematic literature review. The Clinical journal of pain. 2012;28(4):344-54. https://doi.org/10.1097/AJP.0b013e31822ed2f3 PMid:22001667

6. Jamieson-Lega K, Berry R, Brown CA. Pacing: A concept analysis of a chronic pain intervention. Pain Research and Management. 2013;18(4):207-13. https://doi.org/10.1155/2013/686179 PMid:23717825

7. Meana $M$, Cho R, DesMeules M. Chronic pain: the extra burden on Canadian women. BMC women's health. 2004;4(1):1. https://doi.org/10.1186/1472-6874-4-S1-S17

8. Holloway I, Wheeler S. Qualitative research in nursing and healthcare: John Wiley \& Sons; 2013.

9. Chinn PL, Kramer MK. Integrated theory \& knowledge development in nursing: Elsevier Health Sciences; 2013.

10. Walker LO, Avant KC. Strategies for theory construction in nursing. 2005.

11. Hupcey JE, Penrod J. Concept analysis: examining the state of the science. Research and theory for nursing practice. 2005;19(2):197-208. https://doi.org/10.1891/rtnp.19.2.197.66801

12. Rodgers BL. Concept analysis: an evolutionary view. Concept development in nursing: Foundations, techniques, and applications. 2000;2:77-102.

13. Rodgers BL. Philosophical foundations of concept development. Concept development in nursing 2nd ed Philadelphia: Saunders. 2000:7-37.

14. Rafii F, Peyravi $H$, Mehrdad N. Professional socialization in nursing: An evolutionary concept analysis. Journal of hayat. 2010;16(2):15-28.

15. Victor-Chmil J. Critical thinking versus clinical reasoning versus clinical judgment: Differential diagnosis. Nurse Educator. 2013;38(1):34-6. https://doi.org/10.1097/NNE.0b013e318276dfbe PMid:23222632

16. Blau WS. The needle in a haystack. NC Med J. 2013;74(3):215-7. PMid:23940890

17. Jeffery MM, Butler M, Stark A, Kane RL. Multidisciplinary pain programs for chronic noncancer pain. Agency for Healthcare Research and Quality (US), Rockville (MD); 2011.

18. Main CJ, Spanswick CC. Pain management: an interdisciplinary approach: Elsevier Health Sciences; 2000.

19. Mosby I. Mosby's dictionary of medicine, nursing \& health professions: Elsevier Health Sciences; 2013.

20. Fishman SM. Bonica's management of pain: Lippincott Williams \& Wilkins; 2012.

21. Birke $H$, Kurita G, Sjøgren $P$, Højsted J, Simonsen $M$, Juel $K$, et al. Chronic non-cancer pain and the epidemic prescription of opioids in the Danish population: trends from 2000 to 2013. Acta Anaesthesiologica Scandinavica. 2016. https://doi.org/10.1111/aas.12700 PMid:26861026

22. Von Korff M, Dunn KM. Chronic pain reconsidered. Pain. 2008;138(2):267-76. https://doi.org/10.1016/j.pain.2007.12.010 PMid:18226858 PMCid:PMC2613775 
23. Reuben DB, Alvanzo AA, Ashikaga T, Bogat GA, Callahan CM, Ruffing V, et al. National Institutes of Health Pathways to Prevention Workshop: the role of opioids in the treatment of chronic painthe role of opioids in the treatment of chronic pain. Annals of internal medicine. 2015;162(4):295-300. https://doi.org/10.7326/M14-2775 PMid:25581341

24. Chou R, Turner JA, Devine EB, Hansen RN, Sullivan SD, Blazina I, et al. The effectiveness and risks of long-term opioid therapy for chronic pain: a systematic review for a National Institutes of Health Pathways to Prevention Workshop. Annals of internal medicine. 2015;162(4):276-86. https://doi.org/10.7326/M14-2559 PMid:25581257

25. Tauben D. Nonopioid medications for pain. Physical medicine and rehabilitation clinics of North America. 2015;26(2):219-48. https://doi.org/10.1016/j.pmr.2015.01.005 PMid:25952062

26. Welsch P, Sommer C, Schiltenwolf M, Hauser W. [Opioids in chronic noncancer pain-are opioids superior to nonopioid analgesics? A systematic review and meta-analysis of efficacy, tolerability and safety in randomized head-to-head comparisons of opioids versus nonopioid analgesics of at least four week's duration]. Schmerz (Berlin, Germany). 2015;29(1):85-95. https://doi.org/10.1007/s00482-014-1436-0 PMid:25376546

27. Keay KA, Clement $\mathrm{Cl}$, Bandler R. The neuroanatomy of cardiac nociceptive pathways. The nervous system and the heart: Springer; 2000:303-42.

28. Coda B, Bonica J. General considerations of acute pain: In Loeser, D; Bonica, JJ. Bonica's management of pain (3 ed.). Philadelphia: Lippincott Williams \& Wilkins; 2001.

29. Paice JA. Mechanisms and management of neuropathic pain in cancer. J Support Oncol. 2003;1(2):107-20.

30. Bogduk N. Classification of Chronic Pain, Descriptions of Chronic Pain Syndromes and Definitions of Pain Terms: seattle:IASP; 2014.

31. Diagnostic Methods for Neuropathic Pain: A Review of Diagnostic Accuracy. Rapid Response Report: Summary with Critical Appraisal: Canadian Agency for Drugs and Technologies in Health; 2015.

32. D'Arcy Y. Managing chronic pain in acute care. The Nurse Practitioner. 2010;35(12):14-6. https://doi.org/10.1097/01.NPR.0000390442.20875.48 PMid:21088559

33. Boerl RD, Marinusl J, Hiltenl JJ, Huygenl FJ, Eijsl F, Kleefl M, et al. Distribution of signs and symptoms of complex regional pain syndrome type I in patients meeting the diagnostic criteria of the International Association for the Study of Pain. European Journal of Pain. 2011;15(8):830. e1-. e8.

34. Geertzen J, Van Wilgen C, Schrier E, Dijkstra P. Chronic pain in rehabilitation medicine. Disability and rehabilitation. 2006;28(6):363-7. https://doi.org/10.1080/09638280500287437 PMid:16492632

35. Roditi D, Robinson ME. The role of psychological interventions in the management of patients with chronic pain. Psychol Res Behav Manag. 2011;4:41-9. https://doi.org/10.2147/PRBM.S15375 PMid:22114534 PMCid:PMC3218789

36. Turk DC, Wilson HD, Cahana A. Treatment of chronic non-cancer pain. The Lancet. 2011;377(9784):2226-35. https://doi.org/10.1016/S0140-6736(11)60402-9

37. Boulanger A, Clark AJ, Squire P, Cui E, Horbay G. Chronic pain in Canada: have we improved our management of chronic noncancer pain? Pain Research and Management. 2007;12(1):39-47. https://doi.org/10.1155/2007/762180 PMid:17372633

38. Lalonde L, Choinière M, Martin É, Berbiche D, Perreault S, Lussier D. Costs of moderate to severe chronic pain in primary care patients-a study of the ACCORD program. Journal of pain research. 2014;7:389. https://doi.org/10.2147/JPR.S55388 PMid:25045282 PMCid:PMC4094572

39. Robbins WR, Staats PS, Levine J, Fields HL, Allen RW, Campbell JN, et al. Treatment of intractable pain with topical large-dose capsaicin: preliminary report. Anesthesia \& Analgesia. 1998;86(3):579-83. https://doi.org/10.1213/00000539-199803000-00027

40. Beaver WT. Management of cancer pain with parenteral medication. Jama. 1980;244(23):2653-7. https://doi.org/10.1001/jama.1980.03310230051029 PMid:7431615

41. Behar M, Olshwang D, Magora F, Davidson JT. Epidural morphine in treatment of pain. The lancet. 1979;313(8115):527-9. https://doi.org/10.1016/S0140-6736(79)90947-4

42. Woolf CJ, Salter MW. Neuronal plasticity: increasing the gain in pain. Science. 2000;288(5472):1765-8. https://doi.org/10.1126/science.288.5472.1765

43. DeLeo JA, Yezierski RP. The role of neuroinflammation and neuroimmune activation in persistent pain. Pain. 2001;90(1-2):1-6. https://doi.org/10.1016/S0304-3959(00)00490-5

44. Association AN. Nursing's social policy statement: The essence of the profession: Nursesbooks. org; 2010. 
45. Shirazi M, Manoochehri $H$, Zagheri TM, Zayeri F, Alipour V. Explaining of chronic pain management process in older people: a grounded theory study. 2016.

46. Dworkin RH, Turk DC, Wyrwich KW, Beaton D, Cleeland CS, Farrar JT, et al. Interpreting the clinical importance of treatment outcomes in chronic pain clinical trials: IMMPACT recommendations. The Journal of Pain. 2008;9(2):105-21. https://doi.org/10.1016/j.jpain.2007.09.005 PMid:18055266

47. Yousefinezhad OA, Madadi A, Majedzadeh S, Shabannia R, Sadeghian N, Zarinara A, et al. The effect of music therapy on chronic pain in patients with cancer. 2005.

48. Kelly JF, Ritenour AE, McLaughlin DF, Bagg KA, Apodaca AN, Mallak CT, et al. Injury severity and causes of death from Operation Iraqi Freedom and Operation Enduring Freedom: 2003-2004 versus 2006. Journal of Trauma and Acute Care Surgery. 2008;64(2):S21-S7. https://doi.org/10.1097/TA.0b013e318160b9fb PMid:18376168

49. Geniusas S. On naturalism in pain research: a phenomenological critique. Metodo International Studies in Phenomenology and Philosophy. 2013;1(1).

50. Larner D. Chronic pain transition: A concept analysis. Pain Management Nursing. 2014;15(3):707-17. https://doi.org/10.1016/j.pmn.2013.04.003 PMid:23769800

51. Cedraschi C, Allaz A. How to identify patients with a poor prognosis in daily clinical practice. Best Practice \& Research Clinical Rheumatology. 2005;19(4):577-91. https://doi.org/10.1016/j.berh.2005.03.002 PMid:15949777

52. Facione PA, Facione NC. Thinking and reasoning in human decision making: The method of argument and heuristic analysis: Insight Assessment; 2007.

53. Barry DT, Irwin KS, Jones ES, Becker WC, Tetrault JM, Sullivan LE, et al. Integrating buprenorphine treatment into office-based practice: a qualitative study. Journal of general internal medicine. 2009;24(2):218-25. https://doi.org/10.1007/s11606-008-0881-9 PMid:19089500 PMCid:PMC2628993

54. Yarnall KS, Pollak KI, Østbye T, Krause KM, Michener JL. Primary care: is there enough time for prevention? American journal of public health. 2003;93(4):635-41. https://doi.org/10.2105/AJPH.93.4.635 PMid:12660210 PMCid:PMC1447803

55. Becker WC, Sullivan LE, Tetrault JM, Desai RA, Fiellin DA. Non-medical use, abuse and dependence on prescription opioids among US adults: psychiatric, medical and substance use correlates. Drug and alcohol dependence. 2008;94(1):38-47. https://doi.org/10.1016/j.drugalcdep.2007.09.018 PMid:18063321

56. Parish SJ, Ramaswamy M, Stein MR, Kachur EK, Arnsten JH. Teaching about substance abuse with objective structured clinical exams. Journal of general internal medicine. 2006;21(5):453-9. https://doi.org/10.1111/j.15251497.2006.00426.x PMid:16704387 PMCid:PMC1484780

57. Gallagher AM, Leighton-Scott J, van Staa TP. Utilization characteristics and treatment persistence in patients prescribed low-dose buprenorphine patches in primary care in the United Kingdom: a retrospective cohort study. Clinical therapeutics. 2009;31(8):1707-15. https://doi.org/10.1016/j.clinthera.2009.08.022 PMid:19808129

58. Alsaadi SM, McAuley JH, Hush JM, Maher CG. Prevalence of sleep disturbance in patients with low back pain. European Spine Journal. 2011;20(5):737-43. https://doi.org/10.1007/s00586-010-1661-x PMid:21190045 PMCid:PMC3082679

59. Van Dongen HP, Maislin G, Mullington JM, Dinges DF. The cumulative cost of additional wakefulness: doseresponse effects on neurobehavioral functions and sleep physiology from chronic sleep restriction and total sleep deprivation. Sleep-New York then Westchester-. 2003;26(2):117-29. https://doi.org/10.1093/sleep/26.2.117

60. Chung OY, Bruehl S. The impact of blood pressure and baroreflex sensitivity on wind-up. Anesthesia \& Analgesia. 2008;107(3):1018-25. https://doi.org/10.1213/ane.0b013e31817f8dfe PMid:18713923

61. Bruehl S, Chung OY, Ward P, Johnson B, McCubbin JA. The relationship between resting blood pressure and acute pain sensitivity in healthy normotensives and chronic back pain sufferers: the effects of opioid blockade. Pain. 2002;100(1):191-201. https://doi.org/10.1016/S0304-3959(02)00295-6

62. Ambler N, de C Williams AC, Hill P, Gunary R, Cratchley G. Sexual difficulties of chronic pain patients. The Clinical journal of pain. 2001;17(2):138-45. https://doi.org/10.1097/00002508-200106000-00006 PMid:11444715

63. Anderson RU, Wise D, Sawyer T, Chan CA. Sexual dysfunction in men with chronic prostatitis/chronic pelvic pain syndrome: improvement after trigger point release and paradoxical relaxation training. The Journal of urology. 2006;176(4):1534-9. https://doi.org/10.1016/j.juro.2006.06.010 PMid:16952676

64. Ashory A. The prevalence of pain among residents of nursing homes and the impact of pain on their mood and quality of life. Archives of Iranian Medicine. 2006;9(4):368-73. PMid:17061612 
65. Shirazi M, Manoochehri $H$, Zagheri Tafreshi M, Zayeri $F$, Alipour V. Prevalence of chronic pain and its characteristics among elderly people in Ahvaz city: a cross sectional study. Journal of Clinical Nursing and Midwifery 2015;4(3):13-28.

66. McCracken LM, Eccleston C. Coping or acceptance: what to do about chronic pain? Pain. 2003;105(1):197-204. https://doi.org/10.1016/S0304-3959(03)00202-1

67. Risdon A, Eccleston C, Crombez G, McCracken L. How can we learn to live with pain? A Q-methodological analysis of the diverse understandings of acceptance of chronic pain. Social science \& medicine. 2003;56(2):375-86. https://doi.org/10.1016/S0277-9536(02)00043-6

68. Turk DC, Okifuji A. Psychological factors in chronic pain: evolution and revolution. Journal of consulting and clinical psychology. 2002;70(3):678. https://doi.org/10.1037/0022-006X.70.3.678

69. Wang CK, Hah JM, Carroll I. Factors contributing to pain chronicity. Current pain and headache reports. 2009;13(1):7-11. https://doi.org/10.1007/s11916-009-0003-3 PMid:19126364 PMCid:PMC2743454

$\diamond \diamond \diamond \diamond \diamond \diamond \diamond$

http://www.ejgm.co.uk 